\title{
Targeted Radiotherapy of Prostate Cancer with a Gastrin-Releasing Peptide Receptor Antagonist Is Effective as Monotherapy and in Combination with Rapamycin
}

\author{
Rebecca A. Dumont ${ }^{1,2}$, MariaLuisa Tamma ${ }^{3}$, Friederike Braun ${ }^{1}$, Sandra Borkowski ${ }^{4}$, Jean Claude Reubi ${ }^{5}$, \\ Helmut Maecke ${ }^{1,3}$, Wolfgang A. Weber ${ }^{1}$, and Rosalba Mansi ${ }^{1,3}$ \\ ${ }^{I}$ Department of Nuclear Medicine, University of Freiburg, Freiburg, Germany; ${ }^{2}$ Department of Radiology, David Geffen School of \\ Medicine at UCLA, Los Angeles, California; ${ }^{3}$ Institute of Nuclear Medicine, University Hospital Basel, Basel, Switzerland; ${ }^{4}$ Bayer \\ Pharma AG, Global Drug Discovery, Berlin, Germany; and ${ }^{5}$ Department of Pathology, University Hospital Bern, Bern, Switzerland
}

The gastrin-releasing peptide receptor (GRPr) is overexpressed in prostate cancer and is an attractive target for radionuclide therapy. In addition, inhibition of the protein kinase mammalian target of rapamycin (mTOR) has been shown to sensitize various cancer cells to the effects of radiotherapy. Methods: To determine the effect of treatment with rapamycin and radiotherapy with a novel ${ }^{177}$ Lu-labeled GRPr antagonist ( ${ }^{177}$ Lu-RM2, BAY 1017858) alone and in combination, in vitro and in vivo studies were performed using the human $\mathrm{PC}-3$ prostate cancer cell line. PC-3 cell proliferation and ${ }^{177}$ Lu-RM2 uptake after treatment with rapamycin were assessed in vitro. To determine the influence of rapamycin on ${ }^{177} \mathrm{Lu}-\mathrm{RM} 2$ tumor uptake, in vivo small-animal PET studies with ${ }^{68} \mathrm{Ga}-\mathrm{RM} 2$ were performed after treatment with rapamycin. To study the efficacy of ${ }^{177} \mathrm{Lu}-\mathrm{RM} 2$ in vivo, mice with subcutaneous PC-3 tumors were treated with ${ }^{177} \mathrm{Lu}-\mathrm{RM} 2$ alone or after pretreatment with rapamycin. Results: Stable expression of GRPr was maintained after rapamycin treatment with doses up to $4 \mathrm{mg} / \mathrm{kg}$ in vivo. Monotherapy with ${ }^{177} \mathrm{Lu}-\mathrm{RM} 2$ at higher doses (72 and $144 \mathrm{MBq}$ ) was effective in inducing complete tumor remission in $60 \%$ of treated mice. Treatment with $37 \mathrm{MBq}$ of ${ }^{177} \mathrm{Lu}-\mathrm{RM} 2$ and rapamycin in combination led to significantly longer survival than with either agent alone. No treatment-related toxicity was observed. Conclusion: Radiotherapy using a ${ }^{177} \mathrm{Lu}$-labeled GRPr antagonist alone or in combination with rapamycin was efficacious in inhibiting in vivo tumor growth and may be a promising strategy for treatment of prostate cancer.

Key Words: radiopeptide therapy; combination therapy; bombesin antagonist; prostate cancer

J Nucl Med 2013; 54:762-769

DOI: 10.2967/jnumed.112.112169

Received Aug. 1, 2012; revision accepted Nov. 26, 2012.

For correspondence or reprints contact: Rebecca A. Dumont, Department of Radiology, David Geffen School of Medicine at UCLA, 757 Westwood Plaza, Ste. 1638, Los Angeles, CA 90095.

E-mail: rdumont@ucla.edu

Published online Mar. 14, 2013.

COPYRIGHT @ 2013 by the Society of Nuclear Medicine and Molecular Imaging, Inc.
$\mathbf{P}$ rostate cancer continues to be the second leading cause of cancer-related deaths for men in developed countries. Although the 5-y disease-specific survival rate of localized disease treated by surgery or radiotherapy is more than $90 \%$, the effectiveness of systemic therapy for advanced prostate cancer is limited. Currently, depleting or blocking the action of androgens is the standard of care for men with advanced prostate cancer. Androgen deprivation results in a decrease in the concentration of prostate-specific antigen, in tumor regression, and in relief of symptoms in most patients, but the response to treatment is not durable and with time prostate-specific antigen concentrations increase, indicating reactivated androgen-receptor signaling and a transition to a castration-resistant state that is invariably fatal (1).

Docetaxel prolongs survival in the treatment of castration-resistant prostate cancer (2) and is currently the firstline agent for this stage of disease. There is a wide range of toxicities associated with docetaxel given its nonspecific inhibition of microtubule assembly $(3,4)$; therefore, targeted therapies such as protein kinase inhibitors are being evaluated in conjunction with radiotherapy for treatment of advanced prostate cancer $(5,6)$.

When deprived of androgen stimulation, prostate cancer cells develop the ability to survive and thus become androgen-insensitive by upregulating oncogenic pathways in which protein kinases play a crucial role. Phosphoinositide 3-kinase (PI3K)/Akt/mammalian target of rapamycin (mTOR) signaling is upregulated in $30 \%-50 \%$ of prostate cancers, often through loss of the tumor suppressor gene phosphatase and tensin homolog, and alterations of this pathway are associated with increasing tumor stage, grade, and risk of biochemical recurrence $(7,8)$. Rapamycin, a potent and specific inhibitor of mTOR, inhibits tumor growth, angiogenesis, and metastasis as well as induces apoptosis in cancer cell lines and mouse models of cancer (9-11). mTOR inhibition is also known to confer radiosensitivity on some types of human cancers, such as breast, head and neck, and colon cancer, and induce the nonapoptotic cell 
death pathway of autophagy for improved destruction of prostate cancer cells (12).

The gastrin-releasing peptide receptor (GRPr) is overexpressed in a variety of human tumors and is present in a high percentage of prostate cancers; thus, radiolabeled peptides specific for this receptor are of potential use for imaging and targeted radionuclide therapy (13-23). Compared with other targeted therapies, targeted radiotherapy has the advantage of cross-fire irradiation, meaning that an individual tumor cell lacking receptor expression may still receive an adequate dose of radiation from neighboring cells with receptor expression. This concept has become especially important as our understanding of human tumor heterogeneity has evolved.

For imaging and targeted radiotherapy of prostate cancer, several GRPr agonists have been developed (14). The ${ }^{177} \mathrm{Lu}$-labeled GRPr agonist ${ }^{177} \mathrm{Lu}-\mathrm{DO} 3 \mathrm{~A}-\mathrm{CH}_{2} \mathrm{CO}-\mathrm{G}-(4-$ aminobenzoyl)-QWAVGHLM-NH 2 ( ${ }^{177}$ Lu-AMBA) (24) underwent phase I clinical trials in patients with metastatic prostate cancer (25). More recently, we developed the DOTAconjugated GRPr antagonist 4-amino-1-carboxymethyl-piperidine-D-Phe-Gln-Trp-Ala-Val-Gly-His-Sta-Leu-NH 2 (RM2, BAY 1017858), which can be easily labeled with various radionuclides (26). RM2 and other GRPr antagonists have shown a more favorable biodistribution than GRPr agonists (such as ${ }^{177} \mathrm{Lu}-\mathrm{AMBA}$ ) for imaging of prostate cancer in preclinical models. Specifically, pancreatic and intestinal retention of the antagonists has been found to be markedly lower than that for GRPr agonists $(26,27)$. On the basis of these imaging and biodistribution data, we hypothesized that RM2 labeled with the $\beta$-emitter ${ }^{177} \mathrm{Lu}$ may be an effective tool for therapy of prostate cancer.

Agents that sensitize malignant cells to radiation would amplify tumor response while minimizing toxicity to surrounding organs by lowering effective therapeutic doses, a strategy that has been successfully used in other malignant diseases to improve local control and survival outcomes (28-30). In this study, we investigated the novel GRPr antagonist ${ }^{177} \mathrm{Lu}-\mathrm{RM} 2$ (BAY 1017858) alone and in combination with the mTOR inhibitor rapamycin using in vitro and in vivo models of PC-3, an androgen-independent human prostate cancer cell line with known upregulation of the PI3K/Akt/mTOR pathway, with the rationale of sensitizing prostate cancer cells to the effects of radiation by mTOR kinase inhibition.

\section{MATERIALS AND METHODS}

\section{Cell Culture and Reagents}

The human prostate cancer cell line PC-3 was obtained from American Type Culture Collection and cultured in Dulbecco modified Eagle medium supplemented with vitamins, amino acids, penicillin and streptomycin, and $10 \%$ fetal bovine serum in a humidified $5 \% \mathrm{CO}_{2}$ atmosphere at $37^{\circ} \mathrm{C}$. Rapamycin (SigmaAldrich) was obtained in a stock solution of $2.74 \mathrm{mM}$ and diluted in dimethyl sulfoxide (DMSO) for in vitro experiments. RM2 was synthesized and characterized as previously described (26). A ${ }^{68} \mathrm{Ge} /{ }^{68} \mathrm{Ga}$ generator was used to produce ${ }^{68} \mathrm{Ga}$ (Eckert \& Ziegler).
${ }^{177} \mathrm{LuCl}_{3}$ was purchased from Isotope Technologies Garching $\mathrm{GmbH}$.

\section{Radiolabeling}

${ }^{68} \mathrm{Ga}-\mathrm{RM} 2$ was prepared as described by Zhernosekov et al. (31). Briefly, purified ${ }^{68} \mathrm{Ga}(250-300 \mathrm{MBq})$ was used directly for labeling of RM2 $(20 \mu \mathrm{g})$ in $0.2 \mathrm{M} \mathrm{NH}_{4}$-acetate buffer $(2 \mathrm{~mL})$ at $\mathrm{pH} 4$, followed by incubation for $10 \mathrm{~min}$ at $95^{\circ} \mathrm{C}$. ${ }^{177} \mathrm{Lu}-\mathrm{RM} 2$ was prepared by dissolving $10 \mu \mathrm{g}$ of peptide in 250 $\mu \mathrm{L}$ of sodium acetate buffer $(0.4 \mathrm{M}, \mathrm{pH} 5.0)$ and by incubating with ${ }^{177} \mathrm{LuCl}_{3}(110-220 \mathrm{MBq} ; 30-60 \mu \mathrm{L})$ for $30 \mathrm{~min}$ at $95^{\circ} \mathrm{C}$. Quality controls were performed by analytic reversed-phase highperformance liquid chromatography (Knauer) with a photo diode array detector (1200 series; Agilent Technologies) and a flow-through RamonaStar (Raytest GmBH) $\gamma$-detector using a Macherey-Nagel Nucleosil 120 C18 column or a Chromolith Merck RP-18e column (eluents: A, $0.1 \%$ trifluoroacetic acid in water, and B, acetonitrile; gradient 1: 0-30 $\mathrm{min}, 95 \%-30 \% \mathrm{~A}$, and flow, $0.750 \mathrm{~mL} / \mathrm{min}$; gradient 2: 0-3 $\mathrm{min}, 95 \%-50 \% \mathrm{~A}$, and flow, $2.5 \mathrm{~mL} / \mathrm{min})$. For injection, the radioligand was diluted in $0.9 \% \mathrm{NaCl}$ with $0.1 \%$ bovine serum albumin.

\section{Proliferation Assay}

PC-3 cells were plated at a density of 100,000 per well in 12-well plates and incubated overnight. The following day, rapamycin was added to the wells at concentrations ranging between 0.1 and $10 \mathrm{nM}$. After 24, 48, and $72 \mathrm{~h}$, viable cells were counted using a trypan blue exclusion assay. Experiments were performed in triplicate.

\section{GRPr Expression After Rapamycin Treatment}

PC-3 cells were seeded at a density of 50,000-100,000 per well to account for rapamycin-induced growth inhibition in 12-well plates and incubated overnight. Experiments were performed in triplicate. On the day of the experiment, cells were washed twice with phosphate-buffered saline (PBS), and rapamycin-containing medium (0.1-10 $\mathrm{nM}$ ) or control medium (medium with DMSO) was added to each well. The plates were incubated at $37^{\circ} \mathrm{C}$ for 24 and $48 \mathrm{~h}$. At the selected time point, the medium was removed, cells were washed with PBS, and fresh medium containing ${ }^{177} \mathrm{Lu}-$ RM2 (0.8 pmol/well) was added. After incubation at $37^{\circ} \mathrm{C}$ for $2 \mathrm{~h}$, a modified uptake assay based on previously described methods was performed (16). Briefly, ${ }^{177} \mathrm{Lu}$-RM2-containing medium was removed, and cells were washed twice with ice-cold PBS. Cells were trypsinized for $5 \mathrm{~min}$ at $37^{\circ} \mathrm{C}$, after which serum containing medium was added to each well. Half of the contents from each well was used for cell counting, and the other half was used for $\gamma$-counting. $\gamma$-counting was done on a Cobra $5003 \gamma$-system well counter (Packard Instruments).

\section{In Vitro Therapy}

PC-3 cells were seeded at a density of 25,000-100,000 per well depending on the time point in 12-well plates and incubated overnight. Cells were treated with $10 \mathrm{nM}$ rapamycin for $6 \mathrm{~h}$ at $37^{\circ} \mathrm{C}$, after which the drug-containing medium was removed and was replaced with fresh medium containing $1,850 \mathrm{kBq}(50 \mu \mathrm{Ci})$ of ${ }^{177} \mathrm{Lu}-\mathrm{RM} 2$. The cells were returned to the $37^{\circ} \mathrm{C}$ incubator, and cell viability was assessed by a trypan blue exclusion assay after 24, 48, 72, and $96 \mathrm{~h}$.

\section{In Vivo ${ }^{68}$ Ga-RM2 Uptake After Rapamycin Treatment}

Animals were maintained and treated in compliance with the guidelines of the German Law for the use of living animals in scientific studies. Ten female athymic nude mice (age, 6-7 wk; 
weight, 16-18 g) (Harlan) with subcutaneously implanted PC-3 tumors $\left(10^{6}\right.$ cells/mouse) were randomly divided into 2 groups 13 $\mathrm{d}$ after implantation and given intraperitoneal injections of rapamycin $(4 \mathrm{mg} / \mathrm{kg}$ ) in DMSO daily for $3 \mathrm{~d}$ or PBS (untreated). Tumor size at the start of treatment averaged $7 \times 7 \mathrm{~mm}$. After treatment, $0.5 \mathrm{MBq}(0.1 \mathrm{nmol})$ of ${ }^{68} \mathrm{Ga}-\mathrm{RM} 2$ was injected via lateral tail vein cannulation. Animals were anesthetized with $1.5 \%$ isoflurane, and 10-min static scans were acquired at $1 \mathrm{~h}$ after injection using a microPET focus 120 scanner (Siemens Preclinical Solutions). PET images were reconstructed with an ordered-subset expectation maximization algorithm provided by the manufacturer. Image counts per pixel per second were calibrated to activity concentrations $(\mathrm{Bq} / \mathrm{mL})$ by measuring a $3.5-\mathrm{cm}$ cylinder phantom filled with a known concentration of radioactivity. Images were generated using AMIDE software. The color scale was set from $0 \%$ to $5 \%$ to allow for qualitative comparison among the images. Biodistribution studies were performed after completion of smallanimal PET scanning. Samples from the tumor, muscle, and liver were collected for each mouse, rinsed of excess blood, blotted dry, weighed, and measured in a $\gamma$-counter (Cobra 5003; Packard Instruments). Results were expressed as percentage of injected activity per gram of tissue (\%IA/g). A separate group of 6 mice were treated as described above, and GRPr expression was analyzed via autoradiography with $\left[{ }^{125} \mathrm{I}_{-}-\mathrm{Tyr}^{4}\right]$-bombesin $(18)$ on sections of snap-frozen tumor tissue. Results were reported in disintegrations per minute.

\section{Lu-RM2 Biodistribution and Tumor Radiation Dose}

To study the biodistribution of ${ }^{177} \mathrm{Lu}-\mathrm{RM} 2$, groups of 5 athymic nude mice bearing PC-3 tumors were sacrificed at 4 and $72 \mathrm{~h}$ after injection of $0.185,0.925,1.85$, and $4.63 \mathrm{MBq}$ of ${ }^{177} \mathrm{Lu}-\mathrm{RM} 2$ (10, $50,100$, and $250 \mathrm{pmol})$. Organs were collected as described above, and results were expressed as \%IA/g. To estimate the tumor radiation dose, groups of 3-7 animals were sacrificed at 1, 4, 24, 48, and $72 \mathrm{~h}$ after injection of $0.185 \mathrm{MBq}$ of ${ }^{177} \mathrm{Lu}-\mathrm{RM} 2(10 \mathrm{pmol})$. The radioactivity concentration of RM2 was measured as \%IA/g of tumor tissue (without correction for radioactive decay). The area under the tumor time-activity curve was calculated by the trapezoid rule. After the last measured time point, the curve was extrapolated to infinity by assuming that the activity concentration decreases by physical decay only. The SD of the time-activity curve was calculated as described by Yuan (32). Because of the short range of the $\beta$-particles emitted by ${ }^{177} \mathrm{Lu}$, the tumor dose was estimated by multiplying the number of decay events within the tumor tissue with the mean $\beta$-energy of ${ }^{177} \mathrm{Lu}$ and dividing by the tumor mass (i.e., it was assumed that all $\beta$-particles are absorbed within the tumor tissue).

\section{${ }^{177}$ Lu-RM2 Therapy In Vivo}

To assess the therapeutic effect and associated toxicities of ${ }^{177} \mathrm{Lu}-\mathrm{RM} 2$, a fractionated dosing scheme was performed in 25 female athymic nude mice subcutaneously implanted with PC-3 tumors $\left(10^{6}\right.$ cells/mouse). Thirteen days after implantation, mice were randomly divided into 5 groups. Tumor size at the start of treatment averaged $7 \times 7 \mathrm{~mm}$. Three of the groups (groups 1-3) received 3 injections of ${ }^{177} \mathrm{Lu}-\mathrm{RM} 2$ per week (days 0, 2, and 4), and the procedure was repeated (days 14, 16, and 18) after a drugfree week. The total activity injected corresponded to 36,72 , and $144 \mathrm{MBq}$ given in doses of 6, 12, and $24 \mathrm{MBq}(100,200$, and 400 pmol) for groups 1,2 , and 3 , respectively. The fourth group received cold peptide $(200 \mathrm{pmol})$ labeled with the nonradioactive isotope ${ }^{175} \mathrm{Lu}\left({ }^{175} \mathrm{Lu}-\mathrm{RM} 2\right)$, and the fifth group received PBS (un- treated). The mice were monitored 3 times per week by measuring tumor size, appearance, and body mass for up to $150 \mathrm{~d}$. Animals with loss of more than $15 \%$ of their original mass or with a maximum tumor diameter of greater than $20 \mathrm{~mm}$ were sacrificed. Tumor size was measured with calipers in 2 dimensions, and tumor volume was calculated assuming an elliptical shape. Tumor, kidneys, and pancreas were prepared for histologic evaluation.

\section{In Vivo Combination Therapy with ${ }^{177}$ Lu-RM2 and Rapamycin}

The effect of combination therapy on tumor growth was evaluated in vivo using female athymic nude mice with subcutaneous PC-3 xenografts treated with $37 \mathrm{MBq}$ (300 pmol) of ${ }^{177} \mathrm{Lu}-\mathrm{RM} 2$ alone or rapamycin daily (4 mg/kg) for $72 \mathrm{~h}$, followed by $37 \mathrm{MBq}$ of ${ }^{177} \mathrm{Lu}-\mathrm{RM} 2$. Control groups consisted of animals receiving PBS (untreated) or rapamycin $(4 \mathrm{mg} / \mathrm{kg})$ daily for $72 \mathrm{~h}$. Tumor size at the start of treatment averaged $7 \times 7 \mathrm{~mm}$. Animals were monitored daily throughout the course of therapy as described above for up to 160 d. Organs (tumor, kidney, pancreas, and liver) were collected for histology. The experiment was performed twice, first with 5-6 animals per group then repeated with 7 animals per group.

\section{Histology}

Selected mouse organs were dissected from the sacrificed animals and immediately fixed in $10 \%$ neutral buffered formalin at $4^{\circ} \mathrm{C}$. After fixation and routine dehydration, all tissue samples were embedded in paraffin, and 4- to 6- $\mu$ m-thick sections were stained with hematoxylin and eosin for microscopic examination using standard protocols. Macroscopic and microscopic findings were assessed in terms of affected number of organs and severity.

\section{Statistical Analysis}

All in vitro studies were performed in triplicate. Quantitative data were compared by an unpaired 2-tailed $t$ test or 1-way ANOVA. A log-rank test was used to test differences in survival for different groups of animals. All statistical tests were performed with GraphPad Prism (GraphPad Software Inc.).

\section{RESULTS}

\section{Lu-RM2: Favorable In Vivo Biodistribution Profile}

RM2 was synthesized using solid-phase peptide synthesis (Fmoc chemistry). The ${ }^{177} \mathrm{Lu}-\mathrm{RM} 2$ conjugate was obtained with greater than $95 \%$ radiolabeling yield at a maximum specific activity of $37 \mathrm{GBq} / \mu \mathrm{mol} .{ }^{68} \mathrm{Ga}-\mathrm{RM} 2$ was obtained with a specific activity of $25 \mathrm{GBq} / \mu \mathrm{mol}$ and a greater than $95 \%$ radiolabeling yield.

Biodistribution data demonstrate favorable tumor-tonormal tissue ratios at 4 and $24 \mathrm{~h}$. Data from mice injected with $4.63 \mathrm{MBq}$ of ${ }^{177} \mathrm{Lu}-\mathrm{RM} 2(250 \mathrm{pmol})$ are shown in Table 1. No significant difference in radiopeptide biodistribution was seen among mice injected with 10, 50, 100, or 250 pmol of ${ }^{177} \mathrm{Lu}-\mathrm{RM} 2$ (other datasets not shown). Initial uptake of bone marrow and liver was relatively low at $4 \mathrm{~h}$ and further decreased by $24 \mathrm{~h}$, whereas robust tumor uptake of ${ }^{177} \mathrm{Lu}-\mathrm{RM} 2$ was seen at both times. Renal uptake decreased by approximately $44 \%$ over a $24-\mathrm{h}$ period. Supplemental Figure 1 (supplemental materials are available online only at http://jnm.snmjournals.org) shows the tumor time-activity curves for ${ }^{177} \mathrm{Lu}-\mathrm{RM} 2$ in tumorbearing mice. Clearance of activity from the tumor approximates physical decay at $72 \mathrm{~h}$ after injection. The total 
TABLE 1

Biodistribution Results and Tumor-to-Normal Tissue Ratios of ${ }^{177}$ Lu-RM2 in Nude Mice Bearing PC-3 Tumors

\begin{tabular}{|c|c|c|}
\hline \multirow[b]{2}{*}{ Organs } & \multicolumn{2}{|c|}{ Time (h) } \\
\hline & 4 & 24 \\
\hline Blood & $0.07 \pm 0.02$ & $0.01 \pm 0.00$ \\
\hline Heart & $0.05 \pm 0.02$ & $0.02 \pm 0.00$ \\
\hline Liver & $0.31 \pm 0.01$ & $0.16 \pm 0.01$ \\
\hline Spleen & $0.11 \pm 0.01$ & $0.06 \pm 0.01$ \\
\hline Lung & $0.10 \pm 0.01$ & $0.04 \pm 0.01$ \\
\hline Kidney & $2.09 \pm 0.19$ & $0.88 \pm 0.09$ \\
\hline Stomach & $0.51 \pm 0.19$ & $0.05 \pm 0.02$ \\
\hline Intestine & $0.14 \pm 0.03$ & $0.04 \pm 0.00$ \\
\hline Adrenal & $0.59 \pm 0.11$ & $0.49 \pm 0.07$ \\
\hline Pancreas & $0.70 \pm 0.12$ & $0.11 \pm 0.02$ \\
\hline Muscle & $0.03 \pm 0.00$ & $0.01 \pm 0.01$ \\
\hline Bone & $0.12 \pm 0.02$ & $0.10 \pm 0.03$ \\
\hline Tumor & $10.97 \pm 0.99$ & $4.66 \pm 0.44$ \\
\hline \multicolumn{3}{|c|}{ Tumor-to-nontumor ratios } \\
\hline Tumor to blood & 156.7 & 466 \\
\hline Tumor to liver & 35.4 & 29.1 \\
\hline Tumor to kidney & 5.3 & 5.3 \\
\hline Tumor to pancreas & 15.7 & 42.4 \\
\hline Tumor to muscle & 365.7 & 466 \\
\hline
\end{tabular}

Data are $\% \mathrm{IA} / \mathrm{g} \pm \mathrm{SD} ; n=5$.

(measured plus extrapolated) area under the curve was 1.42 $\times 10^{3} \% \mathrm{IA} / \mathrm{g}$ per $\mathrm{h}\left(\mathrm{SD}, 5.00 \times 10^{3} \% \mathrm{IA} / \mathrm{g}\right.$ per $\left.\mathrm{h}\right)$. The estimated tumor dose was $0.84 \mathrm{~Gy} / \mathrm{MBq}$.

\section{Lu-RM2 Therapy as Effective Single Agent in Treating PC-3 Tumors In Vivo}

PC-3 tumor growth was rapid in control groups (untreated animals and animals receiving the cold peptide ${ }^{175} \mathrm{Lu}-\mathrm{RM} 2$ ), and all mice were sacrificed within $30 \mathrm{~d}$ after the start of therapy (Fig. 1). All animals treated with higher doses (a total of 72 or $144 \mathrm{MBq}$ of ${ }^{177} \mathrm{Lu}-\mathrm{RM} 2$ ) initially demonstrated partial reduction in tumor size during the first 50 d. Roughly 2 mo after treatment, 4 of 10 animals (40\%) experienced rapid recurrence of the tumor and were sacrificed. The remaining 6 mice (60\%) showed complete tumor remission and were sacrificed at the end of the study after $150 \mathrm{~d}$. Mice treated with a total of $36 \mathrm{MBq}$ showed an intermediate response, with a median survival of $42 \mathrm{~d}$ before sacrifice because of the large tumor size.

\section{Effect of Rapamycin Treatment on GRPr Expression In Vitro and In Vivo}

${ }^{177} \mathrm{Lu}$-RM2 uptake was preserved after treatment with rapamycin (cellular uptake $48 \mathrm{~h}$ after start of treatment: 104\%, $95 \%$, and $120 \%$ of untreated cells with $0.1 \mathrm{nM}$ rapamycin, $1 \mathrm{nM}$ rapamycin, and $10 \mathrm{nM}$ rapamycin, respectively) (Fig. 2 A). After rapamycin treatment, a dose-dependent reduction in PC-3 proliferation was seen (viable cells $72 \mathrm{~h}$ after start of treatment: $10.00 \times 10^{5}, 8.58 \times 10^{5}, 6.75 \times 10^{5}$, and $4.84 \times 10^{5}$ in untreated, $0.1 \mathrm{nM}$ rapamycin, $1 \mathrm{nM}$ rapamycin, and $10 \mathrm{nM}$ rapamycin, respectively) (Supplemental
Fig. 2). Treatment with rapamycin did not significantly affect the in vivo biodistribution of ${ }^{68} \mathrm{Ga}-\mathrm{RM} 2$ as shown by PET imaging and ex vivo tissue sampling (Figs. 2B and 2C). In fact, there was a trend for a higher tumor uptake of ${ }^{68} \mathrm{Ga}$-RM2 in rapamycin-treated animals $(6.21 \pm 0.74 \%$ IA/g vs. $4.87 \pm 0.69 \% \mathrm{IA} / \mathrm{g}, P=0.04$ ) (Fig. $2 \mathrm{C}$ ). Ex vivo autoradiography confirmed that expression of GRPr does not decrease after treatment with rapamycin (Fig. 2D).

\section{Improved Efficacy of Combination Therapy with ${ }^{177}$ Lu-RM2 and Rapamycin In Vitro and In Vivo}

Rapamycin at $10 \mathrm{nM}$ had the greatest cytostatic effect in PC-3 cells without causing impairment of ${ }^{177} \mathrm{Lu}-\mathrm{RM} 2$ uptake (Supplemental Fig. 2); thus, this dose was chosen for in vitro therapy studies. Combination treatment was more effective than either agent alone (cell viability after $96 \mathrm{~h}$ : $64 \%, 82 \%$, and $53 \%$ of untreated cells with $10 \mathrm{nM}$ rapamycin, $1,850 \mathrm{kBq}[50 \mu \mathrm{Ci}]$ of ${ }^{177} \mathrm{Lu}-\mathrm{RM} 2$, and combination therapy; $P<0.0001$ ) (Fig. 3A).

Combined treatment with rapamycin and ${ }^{177} \mathrm{Lu}-\mathrm{RM} 2 \mathrm{re}-$ sulted in the most pronounced inhibition of tumor growth and the longest survival (Fig. 3B; Supplemental Fig. 3). Median survival was $26 \mathrm{~d}$ for untreated mice and 32, 62, and $82 \mathrm{~d}$ for mice treated with rapamycin alone, with ${ }^{177} \mathrm{Lu}-$ RM2 alone, and with combination therapy, respectively $(P<0.0001, \log$-rank test). Tumor regression was observed for all animals receiving combination therapy, and complete remission was observed in 5 of 13 animals from this group during the 160-d follow-up period. In contrast, tumors progressed rapidly in the untreated and rapamycin-alone groups, and all animals were sacrificed by day 50 of the study (Supplemental Fig. 3). Tumors in animals treated with $37 \mathrm{MBq}$ of ${ }^{177} \mathrm{Lu}-\mathrm{RM} 2$ monotherapy grew more slowly than those treated with rapamycin alone; however, tumors treated with monotherapy progressed more rapidly than tumors in the combination therapy group.

There was no evidence of treatment-related toxicity as evaluated by animal appearance, by body weight loss, or on histologic examination of harvested organs for any of the ${ }^{177} \mathrm{Lu}-\mathrm{RM} 2$ doses used in this study. Animals also tolerated the 4-d course of rapamycin without side effects as evaluated by animal appearance and body weight. Two animals in the combination-therapy group were sacrificed because of intestinal problems, one at day 57 and one at day 82. Given

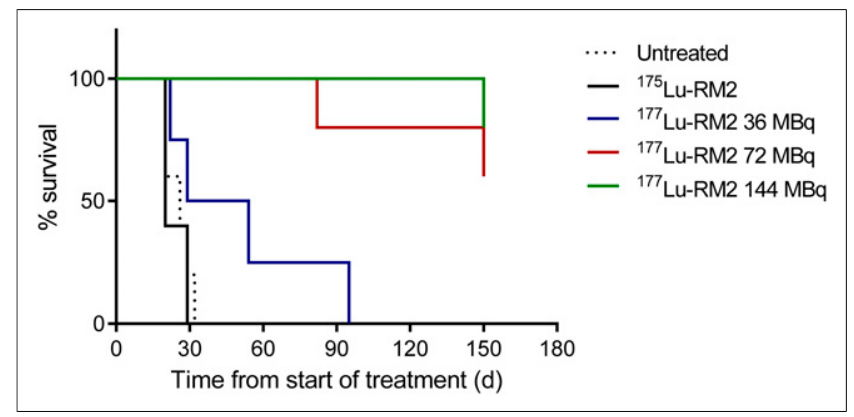

FIGURE 1. Survival curves of untreated and treated mice. 


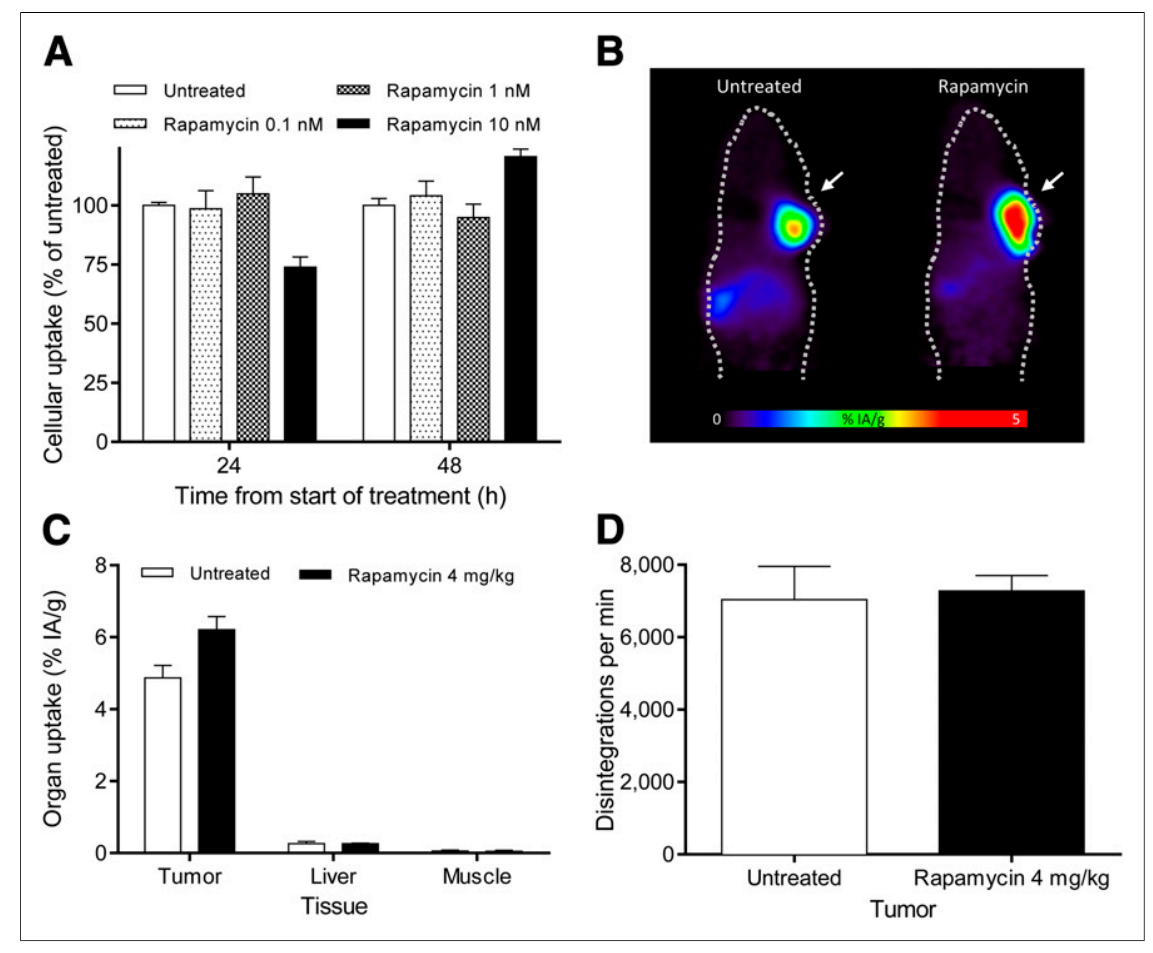

FIGURE 2. (A) In vitro ${ }^{177} \mathrm{Lu}-\mathrm{RM} 2$ uptake assay after rapamycin treatment. (B) ${ }^{68} \mathrm{Ga}-$ RM2 small-animal PET scans of PC-3 tumorbearing mice (arrows) with and without $72 \mathrm{~h}$ of treatment with rapamycin. Biodistribution of tumor, muscle, and liver (C) and autoradiography of tumor samples with ${ }^{125}$-bombesin (D) from untreated and rapamycin-treated animals.

the relatively long delay between drug administration and radiotherapy and onset of symptoms, it is unclear if this represented true treatment-related toxicity. No abnormalities were found on histologic examination of organs collected from animals in the monotherapy and combination-therapy studies (Fig. 3C).

\section{DISCUSSION}

Radiopeptide therapy with the somatostatin analogs ${ }^{90} \mathrm{Y}-$ DOTATOC and ${ }^{177}$ Lu-DOTATATE is frequently used in Europe for the treatment of neuroendocrine tumors. Developed and introduced into clinical practice in 1997, the clinical benefit of this therapy has been documented in several studies. However, despite their successes, the applicability of somatostatin-based radiopeptides remains limited to malignancies expressing the somatostatin receptor, which accounts for a relatively small percentage of all human tumors. In creating the GRP analog RM2, we aimed to develop a peptide-based platform by which to deliver targeted radionuclide therapy to GRPr-expressing tumors, among which is prostate cancer, one of the most common malignancies in men.

Here, we show preclinical evidence that the GRPr antagonist ${ }^{177} \mathrm{Lu}-\mathrm{RM} 2$ can induce remission in tumor-bearing mice in a safe and effective manner. The targeted and specific nature of radiopeptide therapy lends itself to a favorable side-effect profile. In our study, mice tolerated doses of ${ }^{177} \mathrm{Lu}-\mathrm{RM} 2$ up to a total of $144 \mathrm{MBq}$ without evidence of adverse effects. The GRPr is expressed in normal pancreatic tissue with resultant uptake of bombesin-based radiotracers; however, washout of ${ }^{177} \mathrm{Lu}-\mathrm{RM} 2$ from the pancreas occurs after injection and by $24 \mathrm{~h}$ approximates uptake seen in tissues such as the blood pool and muscle. This decrease in tracer retention likely explains the absence of pancreatic damage in the present study.

The most common and concerning side effect seen with radiopeptide therapy is renal toxicity; however, there was no observed damage to the nephrons or renal parenchyma on histologic evaluation of treated mice. Previously, we have reported the favorable biodistribution of ${ }^{111} \mathrm{In}$ - and ${ }^{68} \mathrm{Ga}$-labeled RM2 conjugates, whereby renal excretion led to moderate renal uptake initially with substantial washout by 2 h. Favorable tumor-to-background tissue (blood, kidney, liver, and muscle) ratios were observed at all times ranging from $20 \mathrm{~min}$ to $72 \mathrm{~h}$, and bone marrow uptake was low across all evaluated times (26). We saw similar biodistribution results with the ${ }^{177} \mathrm{Lu}$-labeled RM2 conjugate, which showed favorable tumor-to-background tissue ratios at both 4 and $24 \mathrm{~h}$ after injection. Uptake of ${ }^{177} \mathrm{Lu}-\mathrm{RM} 2$ is maintained in prostate cancer xenografts at $24 \mathrm{~h}$ with an estimated tumor dose of $0.84 \mathrm{~Gy} / \mathrm{MBq}$. Fractionated dosing of 72 or $144 \mathrm{MBq}$ of ${ }^{177} \mathrm{Lu}-\mathrm{RM} 2$ resulted in complete tumor remission in $60 \%$ of animals and prolonged survival in the remaining $40 \%$. Minimal differences were observed in response and survival between animals treated with a total of 72 or $144 \mathrm{MBq}$, which may be due to a nonstochastic effect of the radiation doses on cell death.

Previous work on radiopeptide therapy of prostate cancer has been based on GRPr agonists. Lantry et al. described the efficacy of bombesin agonist ${ }^{177} \mathrm{Lu}$-AMBA in slowing tumor progression in PC-3 tumor-bearing mice with mild kidney toxicity, work that led to the initiation of a phase I clinical trial of ${ }^{177} \mathrm{Lu}-\mathrm{AMBA}$ in patients with prostate cancer (24). The bombesin agonist ${ }^{177}$ Lu-DOTA-8-AOC-BBN 
(7-14) $\mathrm{NH}_{2}$ was evaluated in combination with the chemotherapeutic agents docetaxel and estramustine by Johnson et al. (33). The animals treated with combination therapy survived significantly longer than those treated with either radiopeptide or chemotherapeutic agent alone. Although these results are encouraging, the long uptake and retention of GRPr agonists by the pancreas and intestines is a significant concern for the use of this form of radiopeptide therapy in humans. In addition, therapeutic doses of radiolabeled GRPr agonists have been found to cause significant acute side effects such as nausea and vomiting, most likely due to stimulation of GRPrs in the gastrointestinal tract and subsequent release of intestinal hormones (25).

Previous work has shown that GRPr expression is highest in well-differentiated prostate carcinoma, with one series demonstrating GRPr expression in 30 of 30 locally invasive human prostate cancers. Poorly differentiated and metastatic prostate cancers can show reduced GRPr expression or lose expression altogether (18). Before therapy with ${ }^{177} \mathrm{Lu}-\mathrm{RM} 2$ in humans, a pretherapeutic scan with ${ }^{68} \mathrm{Ga}$ RM2 would be required to demonstrate adequate receptor expression. This method is currently used in patients receiving other forms of radiopeptide therapy (e.g., DOTATOC or DOTATATE).

In the present study, the effect of ${ }^{177} \mathrm{Lu}-\mathrm{RM} 2$ on inhibiting or preventing tumor progression was enhanced when combined with the mTOR inhibitor rapamycin. After mice were pretreated with rapamycin, we saw improved efficacy with $37 \mathrm{MBq}$ of ${ }^{177} \mathrm{Lu}-\mathrm{RM} 2$, a dose that was modestly effective alone. Because of the inhibition of tumor growth, mice lived significantly longer in the combination-therapy group than in the radiopeptide-alone group. Overall, rapamycin was well tolerated in the study alone and in combination with ${ }^{177} \mathrm{Lu}-\mathrm{RM} 2$ at a dose of $4 \mathrm{mg} / \mathrm{kg}$. These findings suggest that the amount of radioactivity needed for effective radiopeptide therapy, and the risk for radiation-induced damage to normal organs, can be decreased by combining radiopeptide therapy with mTOR inhibitors.

mTOR inhibitors are routinely used in the clinic to prevent transplant rejection, and several agents are currently approved for the treatment of various malignancies. Everolimus was approved by the Food and Drug Administration in 2009 for treatment of refractory renal cell carcinoma and received approval earlier this year for use in patients with progressive pancreatic tumors of neuroendocrine origin. Generally, these medications are considered safe, with side effects that are limited and clinically manageable. There is a strong rationale for mTOR inhibition in advanced prostate cancer given the high prevalence of activation of the PI3K/ AKT pathway due largely to the loss of expression-function of the tumor suppressor phosphatase and tensin homolog and the association of this pathway with adverse pathologic features, recurrence after radical prostatectomy, and systemic treatment resistance $(7,8,34)$.

Although the exact mechanism underlying radiosensitization of rapamycin-treated tumors is unknown, mTOR inhibition is associated with induction of autophagy in irradiated cells (12). Furthermore, inhibition of the PI3K/ AKT/mTOR pathway has been found to arrest cancer cells in the G2 M phase of the cell cycle $(35,36)$. Given that cells are often most radiosensitive in the G2 M phase, the cell cycle regulatory effects may contribute to the enhanced antitumor effects that are seen when mTOR inhibitors are combined with ionizing radiation by synchronizing cancer cells to the stage of growth in which they are most likely to experience irreparable damage.

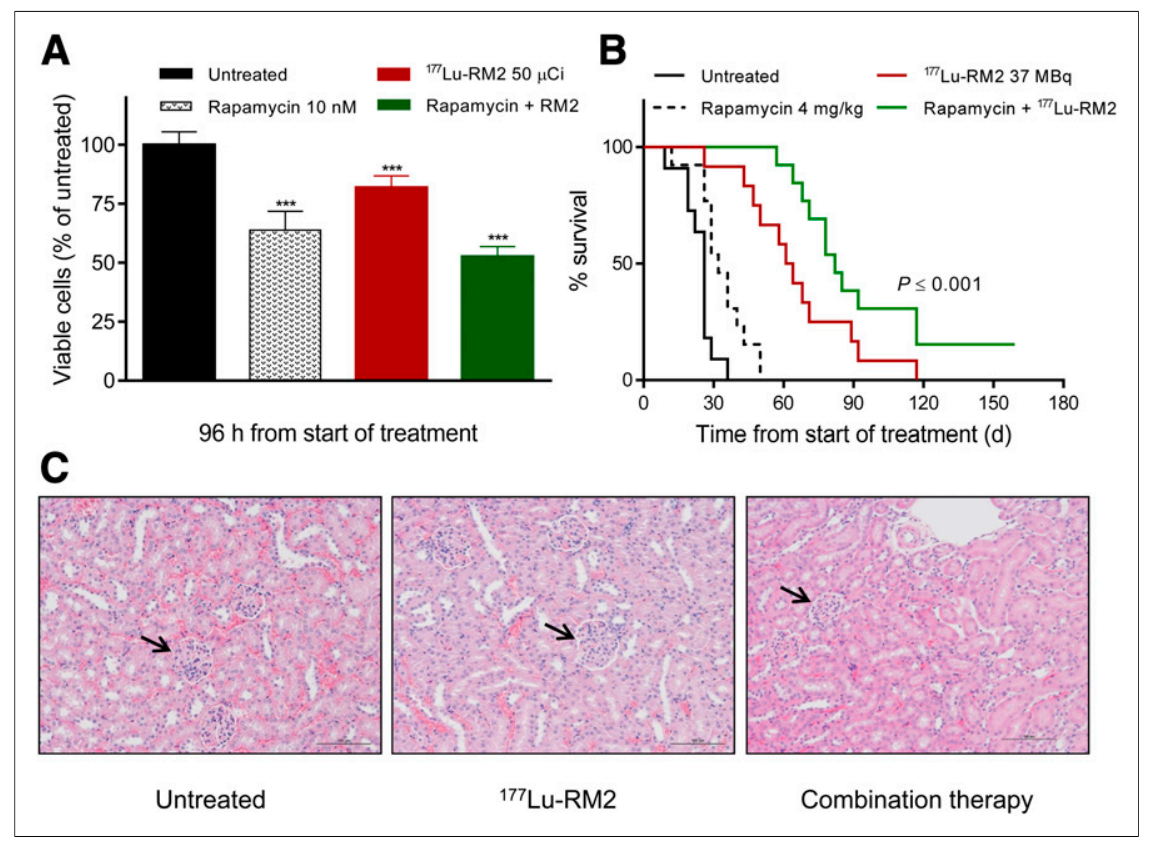

FIGURE 3. (A) In vitro therapy study evaluating effect of combination therapy in $\mathrm{PC}-3$ cells. (B) Survival curves of untreated mice and mice treated with rapamycin alone, ${ }^{177}$ Lu-RM2 alone, or combination therapy. (C) Representative hematoxylin and eosin sections from kidneys of untreated mouse, mouse treated with $144 \mathrm{MBq}$ of ${ }^{177} \mathrm{Lu}-\mathrm{RM} 2$, and mouse from combination-therapy group. Arrows demonstrate intact nephrons. Samples from both treated mice were obtained at conclusion of respective studies. Control sample was obtained $3 \mathrm{wk}$ after start of treatment. ${ }^{\star \star \star} P<0.0001$. 
Further work to elucidate the synergistic interaction between ${ }^{177} \mathrm{Lu}-\mathrm{RM} 2$ and mTOR inhibition in the treatment of prostate cancer is necessary, as are experiments to determine ideal dosing schemes and therapy regimens. On the basis of evidence suggesting mTOR inhibition sensitizes cells to ionizing radiation, we chose to pursue a pretreatment strategy with rapamycin because we felt that this was the most straightforward method to evaluate whether rapamycin before ${ }^{177} \mathrm{Lu}-\mathrm{RM} 2$ treatment would have an additive effect. However, alternative methods such as concurrent mTOR inhibitor or radiopeptide therapy or mTOR inhibitor treatment with fractionated radiopeptide dosing should be evaluated. Furthermore, a plethora of preclinical data have emerged indicating that treatment with various protein kinase inhibitors confers radiosensitivity on prostate cancer models, including those that target Akt, sphingosine kinase, aurora kinase A and B, and Wee1 (37-41). Most of these studies used external-beam radiation; however, 1 group reported additive effects when a ${ }^{177}$ Lu-labeled anti-Lewis $\mathrm{Y}$ monoclonal antibody was combined with an epidermal growth factor receptor kinase inhibitor in an in vivo prostate cancer model (42).

\section{CONCLUSION}

We demonstrated that the GRPr antagonist ${ }^{177} \mathrm{Lu}-\mathrm{RM} 2$ is suitable for targeted radiotherapy of prostate cancer. Because of its high tumor uptake and rapid clearance from normal organs, ${ }^{177} \mathrm{Lu}-\mathrm{RM} 2$ was effective in treating PC-3 xenografts without significant side effects. The efficacy of ${ }^{177} \mathrm{Lu}-\mathrm{RM} 2$ therapy was further increased by pretreatment with rapamycin. These data warrant further research investigating radiolabeled GRPr antagonists alone and in combination with other molecularly targeted therapies in the treatment of prostate cancer.

\section{DISCLOSURE}

The costs of publication of this article were defrayed in part by the payment of page charges. Therefore, and solely to indicate this fact, this article is hereby marked "advertisement" in accordance with 18 USC section 1734. This study was supported in part by Bayer Pharma AG, European Community for the TARCC (no. HEALTH-F2-2007201962) Project within the 7th Framework project, the Swiss National Science Foundation (320000-11833), the Deutsche Forschungsgemeinschaft (DFG) SFB 850, and COST BM0607. No other potential conflict of interest relevant to this article was reported.

\section{ACKNOWLEDGMENTS}

We thank Dr. Melpomeni Fani, Yvonne Kiefer, and Roswitha Tönnesmann for assistance with animal experiments and radiopeptide labeling. We thank Joerdis Luebke and Dr. Michael Mix for support with the small-animal PET.

\section{REFERENCES}

1. Scher HI, Sawyers CL. Biology of progressive, castration-resistant prostate cancer: directed therapies targeting the androgen-receptor signaling axis. $\mathrm{J}$ Clin Oncol. 2005;23:8253-8261.

2. Tannock IF, de Wit R, Berry WR, et al. Docetaxel plus prednisone or mitoxantrone plus prednisone for advanced prostate cancer. $N$ Engl J Med. 2004;351: 1502-1512.

3. Figg WD, Arlen P, Gulley J, et al. A randomized phase II trial of docetaxel (taxotere) plus thalidomide in androgen-independent prostate cancer. Semin Oncol. 2001;28:62-66.

4. Amato RJ, Sarao H. A phase I study of paclitaxel/doxorubicin/thalidomide in patients with androgen-independent prostate cancer. Clin Genitourin Cancer. 2006;4:281-286

5. Amato RJ, Jac J, Mohammad T, Saxena S. Pilot study of rapamycin in patients with hormone-refractory prostate cancer. Clin Genitourin Cancer. 2008;6: 97-102.

6. Yu EY, Massard C, Gross ME, et al. Once-daily dasatinib: expansion of phase II study evaluating safety and efficacy of dasatinib in patients with metastatic castration-resistant prostate cancer. Urology. 2011;77:1166-1171.

7. McCall P, Witton CJ, Grimsley S, Nielsen KV, Edwards J. Is PTEN loss associated with clinical outcome measures in human prostate cancer? Br J Cancer. 2008;99:1296-1301.

8. Shukla S, Maclennan GT, Hartman DJ, Fu P, Resnick MI, Gupta S. Activation of PI3K-Akt signaling pathway promotes prostate cancer cell invasion. Int J Cancer. 2007;121:1424-1432.

9. Guba M, Koehl GE, Neppl E, et al. Dosing of rapamycin is critical to achieve an optimal antiangiogenic effect against cancer. Transpl Int. 2005;18:89-94.

10. Guba M, Yezhelyev M, Eichhorn ME, et al. Rapamycin induces tumor-specific thrombosis via tissue factor in the presence of VEGF. Blood. 2005;105: 4463-4469.

11. Konings IR, Verweij J, Wiemer EA, Sleijfer S. The applicability of mTOR inhibition in solid tumors. Curr Cancer Drug Targets. 2009;9:439-450.

12. Cao C, Subhawong T, Albert JM, et al. Inhibition of mammalian target of rapamycin or apoptotic pathway induces autophagy and radiosensitizes PTEN null prostate cancer cells. Cancer Res. 2006;66:10040-10047.

13. Chen X, Park R, Hou Y, et al. microPET and autoradiographic imaging of GRP receptor expression with ${ }^{64} \mathrm{Cu}$-DOTA-[Lys3]bombesin in human prostate adenocarcinoma xenografts. J Nucl Med. 2004;45:1390-1397.

14. Maecke HR, Hofmann M, Haberkorn U. ${ }^{68} \mathrm{Ga}$-labeled peptides in tumor imaging. J Nucl Med. 2005;46(suppl 1):172S-178S.

15. Van de Wiele C, Dumont F, Vanden Broecke R, et al. Technetium-99m RP527, a GRP analogue for visualisation of GRP receptor-expressing malignancies: a feasibility study. Eur J Nucl Med. 2000;27:1694-1699.

16. Zhang H, Chen J, Waldherr C, et al. Synthesis and evaluation of bombesin derivatives on the basis of pan-bombesin peptides labeled with indium-111, lutetium-177, and yttrium-90 for targeting bombesin receptor-expressing tumors. Cancer Res. 2004;64:6707-6715.

17. Reubi JC. Peptide receptors as molecular targets for cancer diagnosis and therapy. Endocr Rev. 2003;24:389-427.

18. Markwalder R, Reubi JC. Gastrin-releasing peptide receptors in the human prostate: relation to neoplastic transformation. Cancer Res. 1999;59:1152-1159.

19. Garrison JC, Rold TL, Sieckman GL, et al. In vivo evaluation and small-animal PET/CT of a prostate cancer mouse model using ${ }^{64} \mathrm{Cu}$ bombesin analogs: sideby-side comparison of the CB-TE2A and DOTA chelation systems. J Nucl Med. 2007;48:1327-1337.

20. Lears KA, Ferdani R, Liang K, et al. In vitro and in vivo evaluation of ${ }^{64} \mathrm{Cu}-$ labeled SarAr-bombesin analogs in gastrin-releasing peptide receptor-expressing prostate cancer. J Nucl Med. 2011;52:470-477.

21. Breeman WA, de Jong M, Erion JL, et al. Preclinical comparison of ${ }^{111}$ In-labeled DTPA- or DOTA-bombesin analogs for receptor-targeted scintigraphy and radionuclide therapy. J Nucl Med. 2002;43:1650-1656.

22. Prasanphanich AF, Nanda PK, Rold TL, et al. [ ${ }^{64} \mathrm{Cu}-\mathrm{NOTA}-8$-Aoc-BBN(7-14) $\mathrm{NH} 2]$ targeting vector for positron-emission tomography imaging of gastrin-releasing peptide receptor-expressing tissues. Proc Natl Acad Sci USA. 2007;104: 12462-12467.

23. Van de Wiele C, Dumont F, Dierckx RA, et al. Biodistribution and dosimetry of ${ }^{99 \mathrm{~m}}$ Tc-RP527, a gastrin-releasing peptide (GRP) agonist for the visualization of GRP receptor-expressing malignancies. J Nucl Med. 2001;42:1722-1727.

24. Lantry LE, Cappelletti E, Maddalena ME, et al. ${ }^{177} \mathrm{Lu}-\mathrm{AMBA}$ : synthesis and characterization of a selective ${ }^{177} \mathrm{Lu}$-labeled GRP-R agonist for systemic radiotherapy of prostate cancer. $J$ Nucl Med. 2006;47:1144-1152.

25. Bodei L, Ferrari M, Nunn A, et al. ${ }^{177} \mathrm{Lu}$-AMBA Bombesin analogue in hormone refractory prostate cancer patients: a phase I escalation study with single-cycle 
administrations. Paper presented at: Annual Congress, European Association of Nuclear Medicine; Oct 13-17, 2007; Copenhagen, Denmark

26. Mansi R, Wang X, Forrer F, et al. Development of a potent DOTA-conjugated bombesin antagonist for targeting GRPr-positive tumours. Eur J Nucl Med Mol Imaging. 2011;38:97-107.

27. Mansi R, Wang X, Forrer F, et al. Evaluation of a 1,4,7,10-tetraazacyclododecane1,4,7,10-tetraacetic acid-conjugated bombesin-based radioantagonist for the labeling with single-photon emission computed tomography, positron emission tomography, and therapeutic radionuclides. Clin Cancer Res. 2009;15:5240-5249.

28. Dobrowsky W, Huigol NG, Jayatilake RS, et al. AK-2123 (Sanazol) as a radiation sensitizer in the treatment of stage III cancer cervix: initial results of an IAEA multicentre randomized trial. J Cancer Res Ther. 2005;1:75-78.

29. Riahi Idrissi H, Chargari C, Bollet MA, et al. Concurrent whole-brain radiotherapy with trastuzumab for treatment of brain metastases in breast cancer patients: questions and answers. Bull Cancer. 2011;98:425-432.

30. Tejani MA, Cohen RB, Mehra R. The contribution of cetuximab in the treatment of recurrent and/or metastatic head and neck cancer. Biologics. 2010;4:173-185.

31. Zhernosekov KP, Filosofov DV, Baum RP, et al. Processing of generator-produced ${ }^{68} \mathrm{Ga}$ for medical application. J Nucl Med. 2007;48:1741-1748.

32. Yuan J. Estimation of variance for AUC in animal studies. J Pharm Sci. 1993; 82:761-763.

33. Johnson CV, Shelton T, Smith CJ, et al. Evaluation of combined ${ }^{177}$ Lu-DOTA-8AOC-BBN (7-14)NH(2) GRP receptor-targeted radiotherapy and chemotherapy in PC-3 human prostate tumor cell xenografted SCID mice. Cancer Biother Radiopharm. 2006;21:155-166.
34. Pourmand G, Ziaee AA, Abedi AR, et al. Role of PTEN gene in progression of prostate cancer. Urol J. 2007;4:95-100.

35. Manegold PC, Paringer C, Kulka U, et al. Antiangiogenic therapy with mammalian target of rapamycin inhibitor RAD001 (Everolimus) increases radiosensitivity in solid cancer. Clin Cancer Res. 2008;14:892-900.

36. Shinohara ET, Cao C, Niermann K, et al. Enhanced radiation damage of tumor vasculature by mTOR inhibitors. Oncogene. 2005;24:5414-5422.

37. Bridges KA, Hirai H, Buser CA, et al. MK-1775, a novel Wee1 kinase inhibitor, radiosensitizes p53-defective human tumor cells. Clin Cancer Res. 2011;17: 5638-5648.

38. Konsoula Z, Cao H, Velena A, Jung M. Adamantanyl-histone deacetylase inhibitor H6CAHA exhibits favorable pharmacokinetics and augments prostate cancer radiation sensitivity. Int J Radiat Oncol Biol Phys. 2011;79:1541-1548.

39. Moretti L, Niermann K, Schleicher S, et al. MLN8054, a small molecule inhibitor of aurora kinase a, sensitizes androgen-resistant prostate cancer to radiation. Int J Radiat Oncol Biol Phys. 2011;80:1189-1197.

40. Pchejetski D, Bohler T, Brizuela L, et al. FTY720 (fingolimod) sensitizes prostate cancer cells to radiotherapy by inhibition of sphingosine kinase-1. Cancer Res. 2010;70:8651-8661.

41. Rudner J, Ruiner CE, Handrick R, Eibl HJ, Belka C, Jendrossek V. The Aktinhibitor Erufosine induces apoptotic cell death in prostate cancer cells and increases the short term effects of ionizing radiation. Radiat Oncol. 2010; 5:108.

42. Kelly MP, Lee ST, Lee FT, et al. Therapeutic efficacy of ${ }^{177}$ Lu-CHX-A"-DTPAhu3S193 radioimmunotherapy in prostate cancer is enhanced by EGFR inhibition or docetaxel chemotherapy. Prostate. 2009;69:92-104. 